Foreign Born Populations and Unemployment in the United States:

\section{Myth or Reality?}

Steven Doncaster

Senior, Political Science and Economics

\section{Introduction:}

Immigration has played a vital role in the United States, as it has allowed the country to grow a diverse labor force and citizenry. While immigration has been a backbone to economic prosperity throughout the history of the United States, it has also been a key source of political division. As new labor enters the workforce, the increase in competition for jobs has been speculated to have a downward pressure on wages which proponents of stricter immigration policies say have a negative effect on the income of United States citizens. In addition, immigrants are often scapegoats of angry sentiments about job loss in the constantly changing economy. These two key trends came to the forefront as recently as the 2016 presidential election, where US President Donald Trump made a successful bid for the presidency playing to these notions.

As these claims have come up time and time again, it's important to look beyond the perceptions that we may come to from incomplete experience and look at the data. Do areas with higher foreign born populations actually have more unemployment? In order to answer this question, I will be looking at US Congressional district data from all 435 districts to see if there is a link between districts with higher foreign born populations and unemployment. This issue is important to study, as the prevalence of immigrant populations and their discrimination in the political sphere has been a consistently repeating phenomena in US politics. By conducting this research, the data will be able to eliminate biases that our individual perceptions have and bring us to a clear answer of whether foreign born populations impact employment rates in the United States.

\section{Literature Review:}

To see where the current literature has focused on this issue, I have looked at articles published in the last decade that touch on the unemployment rate and immigrants, as I assume that immigrants and the foreign born population have a high level of crossover. The first two articles bring insight and results from Europe. First, an econometric study conducted in Europe on the relationship between the unemployment rate and anti-immigrant sentiments found that the presence of far right parties coupled with a higher unemployment rate sparked anti-immigrant sentiments, while the absence of a far right party did not spark these sentiments (Cochrane and Nevitte 2014, 18-19). While this does not include measurements directly relating unemployment of foreign born populations, it does confirm that this is a relation that is seen as connected by the public, and justifies a variable in my study I will discuss later. Next, an econometric 
study that explores wage setting data from Germany shows that "a one percent increase in the German labor force through immigration increases the unemployment rate by less than 0.1 percentage points"(Brucker and Jahn 2009, 26). This study shows that in Germany, an increase in the immigrant work force produces a small increase in the unemployment rate. While these two papers provide insight and data for us to work with, it is important to also review literature that deals with this topic in the United States.

Starting with a study that provides an overview challenging the claim that immigrants steal jobs, Niyimbanira finds that immigrants overall tend to bring more consumers to a given location, which increases demand for more workers to meet their needs (Niyimbanira and Madzivhandila 2012 , 171-172). This directly challenges the question at hand, as it provides evidence and economic rationale for the unemployment rate to drop when immigrants come to a community. Next, in an econometric study conducted by Orozco-Aleman and Gonzalez-Lozano, they seek to see if immigration and border policies have an effect on the amount of illegal workers in the US. While their main study is not directly linked to mine, one of their key findings is that when illegal workers are on payroll and paying taxes, they reduce the rise in the unemployment rate brought on by illegal workers (Orozco-Aleman and Gonzalez-Lozano 2018, 175). This links illegal workers to a rise in the unemployment rate for natural and legal citizens, which adds an interesting element for my project. Although the illegal immigrant population is often targeted in political discourse around the subject, measuring how many illegal immigrants are in the country is hard to quantify. In order to address this problem, data will be used in this study which tries to best capture the undocumented immigrant population in the United States.

Finally, the well-known labor economist George Borjas and his literature review titled Immigration and the American Worker will help piece together the importance of my research project. In the extensive literature review which covers immigrant's impact on labor, only one focuses on the relationship between the unemployment rate and immigration. This is a study conducted to see how the Mariel boatlift, which was Fidel Castro's announcement that Cuban refugees could freely leave the island in Mariel, Cuba, shows that the unemployment rate for Miami's black population increased during the years of mass Cuban refugee increases. However, the unemployment rate increase for black Americans in Miami increased lower than the national average, as the study focuses on the years 1980-1982 when an economic recession was occurring nationwide (Borjas 2006, 18). These statistics show that one could interpret an increase due to immigrants or that immigrants lowered the increase in the unemployment rate. However, the rest of the paper focuses on the impact that immigrants have on wages of US workers, 
showing the focus the academic field has given this relationship instead.

Overall, the literature on this subject is diverse in its scope and largely unsettled in coming to a final conclusion. What my research looks to add to this topic is a more direct examination of the relationship between the unemployment rate and the foreign born population, as political discourse focuses on this relationship while the academic field tends to focus on the foreign born population and wages. To ground my project in this political discourse, I will be examining the relationship between the unemployment rate and foreign born populations across congressional districts. Outside of a few cases I will discuss below, this level of analysis makes the population sizes of each case relatively similar. I will also be adding in a partisanship measure to account for if this adds to the unemployment rate. The rationale behind this is that if high foreign born population districts and partisan districts are both connected to a high unemployment rate, this partisanship could be caused by the local suspicion of the foreign born population. By incorporating all of these elements, my project seeks to add to the literature of unemployment and foreign born populations.

\section{Hypothesis and model:}

Through this study, I will seek to see if there is a relationship between the foreign born population and the unemployment rate in the United States. This project will help further analyze the effect of Say's law in the United States. Say's law says that supply will create its own demand, and therefore will even out in the long run. In this model, Say's law is relevant to the entrant of a new immigrant (someone who is foreign born), as they are both a worker (supply of labor) and a consumer (demand of goods and services). This project will therefore be able to test whether or not the foreign born population is creating too much demand and lowering the unemployment rate, creating too much labor supply and increasing the unemployment rate, or following Say's law and having an evening out effect. In addition, this is a relationship that has been questioned throughout the United States history, as the nation has consistently had a stream of immigrants coming to the country and a domestic workforce that has had varying levels of hostility towards them. Therefore, this project is significant, as it works towards finding an answer to not only an economically important question but a politically important question as well.

The level of analysis of this project will take place at the US Congressional District level, as they are generally formed to have a relatively equal population size. The only cases in which this does not occur are the seven states that have 1 US House of Representatives seat, as their whole population will be in one district. However, the average population of the Congressional districts in this study is 746,000 , and four of these districts fall within 150,000 of this average. Given that only 3 of the 435 districts lay far outside of the average district size, I do not believe this will significantly impact the results of the study. 
In addition to this relatively similar population size across congressional districts, the populations within the districts are also likely exposed to similar local laws affecting employment and the labor force, which could be influential. In addition, congressional districts are exposed to political ads of the same congressional candidates, so I believe people would partially form their opinions on immigration based on these, which adds another common characteristic across this level of analysis.

To set up a model which will more precisely measure the impact that a foreign born population has on the unemployment rate in the United States, I will incorporate into the model multiple variables that can have an effect on someone being unemployed in addition to the foreign born population. These will include the labor force, income, distance, education, industrial representation, and political partisanship.

The labor force size, industrial representation, and education will be included in the model as I believe they play a significant role in labor market relations that could potentially be cast to foreign born populations if the relationship one has to them are negative. The labor force size essentially determines the amount of people that one has to compete with to find a job. For this reason alone, it is an important part of our model. In addition to this, the labor force is also relatively constrained to a working aged population, which hinders those who are too young or in retirement from participating. Not only will a labor force size tell us something about job competition, but it could inform us on the relationship between age of a population and the unemployment rate.

Industrial representation is also an important feature to take into consideration, as the amount of firms and the diversity of firms will create a varying level of demand for a diversely skilled labor force, which will have an impact on the unemployment rate. Finally, I will take into account educational attainment, as many positions require a certain degree of education to apply for said position. A more educated population could have an effect on the amount of people being able to work, and therefore it must be included in this model. This summarizes the labor market qualities that could have an effect on our model to precisely measure the foreign born population's effect, and which each represent a variable in the model.

In addition to these variables, I will also be controlling for income, distance, and political partisanship for each case. Income is a crucial variable to control for unemployment, as the amount of money in a given area affects the amount of capital invested in an area and in turn the ability to create jobs. People who are paid more will spend more money, creating a cycle which effects the job creation in the area. The distance one has to travel to work in the area of each case also needs to be controlled for. This is because the geographic size is not taken into consideration when congressional districts are formed, but only the size of the population. This means most districts are similar in the amount of people in them, but 
not the closeness of these people. The larger geographic districts or the more densely populated districts could be affecting the amount of traveling someone has to do, which could dissuade people from finding employment if the distance is far. Finally, partisanship will be controlled for, as these localities will be more likely to have local economic and labor policies which reflect the public officials they elect to office. If these districts overwhelmingly skew liberal or conservative, they could be facing benefits from this or hurting from these partisan political tendencies. Districts could be harmed by the motives of political ideology over other considerations, or benefit from these policies or the stability of the policies so that private firms can know what to expect in their respective districts. By including this measure, we will be able to see if partisan biases in areas do have a relationship to unemployment rates.

Taking all of these variables into consideration, I have created the following model for this research project:

$$
\begin{aligned}
& Y=\beta_{0}+\beta_{1} X_{1}+\beta_{2} X_{2}+\beta_{3} X_{3}+\beta_{4} X_{4}+ \\
& \beta_{5} X_{5}+\beta_{6} X_{6}+\beta_{7} X_{7}+u
\end{aligned}
$$

Where:

\begin{tabular}{|ll|}
\hline$Y=$ Unemployment rate & $X_{4}=$ Educational Attainment \\
$X_{1}=$ Foreign born population & $X_{3}=$ Income \\
$X_{2}=$ Labor force size & $X_{6}=$ Distance \\
$X_{3}=$ Industrial representation & $X_{7}=$ Partisanship \\
\hline
\end{tabular}

\section{Data:}

Since this project is using congressional districts as the level of analysis, the United States Census Bureau and their data tool My Congressional District is where data for all the variables, except for the partisanship measure will come from. This data uses results from the 2017 American Community Survey 1-Year Estimates and 2016 County Business Patterns, which are used to represent the beginning of the $115^{\text {th }}$ congress on January 20 ${ }^{\text {th }}, 2017$ (US Census Bureau, 2017).

Using this data, it is important to clarify the definitions that the Census Bureau uses for each of the categories, as they affect the scope of the data.

Two crucial definitions for this project will be the way in which the Census Bureau defines and measures the foreign born population and unemployment rate. For them, the foreign born population is anyone who is not a U.S. citizen at birth, including those who become U.S. citizens through naturalization (US Census Bureau, 2017). This will help us accurately capture individuals who may face discrimination in being employed due to how they gained their legal status and also those who are stereotypically perceived as immigrants by United States citizens by birth. In addition, the census bureau includes illegal immigrants in this definition, allowing us to account for them in this study. For the unemployment rate, the Census Bureau defines this as the number of unemployed people as a percentage of the civilian labor force, giving a clear cut definition which 
connects to our measure of the labor force (US Census Bureau, 2017). In order to measure the labor force, I will be using the data that the Census Bureau calls the civilian labor force. They include in this measure "All non-institutionalized civilians who are either employed or unemployed," which will help the study accurately measure all of those who are searching for work (US Census Bureau, 2017).

Other variables for this project do not have as specific of definitions, but the measurements selected have a purpose. For income, I will be using median household income, as this takes away possible skews in data from extremely wealthy or poor families and situates the data at the median family. For educational attainment, I have decided to use the percentage of the population 25 and over that has a bachelor's degree, as this level of education has been commonly referred to as being a more well off benchmark compared to a high school diploma. There is a large disparity between these two attainments in most districts (US Census Bureau, 2017), so this will make for a compelling measurement. For distance, I will be using the average travel time it takes to get to work, as I believe this will accurately measure what individuals account for when considering employment instead of the actual distance. This will lead to results that include a measure more transparent to the average worker. Finally, for the industrial representation, I will be using the total establishments for all sectors in the economy of a given district, as more firms will allow for more options for workers.
Conceding that this does not take diversity of industries directly into consideration, I operate under the assumption that more total firms will more likely have a diversity of economic sectors than less total firms in a district.

For partisanship, I will be using The Cook Report's rating system which takes how strongly each congressional district leans towards one party and compares this to the national average (The Cook Report, 2018). The results in the dataset therefore show how much the district skews towards one party relative to the United States as a whole. I find that this will be an accurate measure to gage how partisan a district will be, as liberals tend to align to the Democratic party and conservatives to the Republican party. The highest a district can score is difficult to exactly tell, as the national average for each party in elections usually falls in the

\section{$\underline{\text { Summary Statistics Table }}$}

\begin{tabular}{|c|c|c|c|}
\hline Category & Mean & Min. & Max. \\
\hline $\begin{array}{l}\text { Unemployment } \\
\text { rate (\%) }\end{array}$ & 5.4 & 2.7 & 13.4 \\
\hline $\begin{array}{l}\text { \% population } \\
\text { foreign born }\end{array}$ & 13.6 & .1 & 56.3 \\
\hline $\begin{array}{l}\text { civilian labor } \\
\text { force (in 000's) }\end{array}$ & 375 & 215 & 714 \\
\hline $\begin{array}{l}\text { Avg. travel time } \\
\text { to work (min) }\end{array}$ & 27 & 16 & 47 \\
\hline $\begin{array}{l}\text { \% population } \\
\text { over } 25 \text { w BA }\end{array}$ & 32 & 8 & 74 \\
\hline
\end{tabular}




\begin{tabular}{l|c|c|c|}
\hline $\begin{array}{l}\text { \# of } \\
\text { establishments (in } \\
\text { 000's) }\end{array}$ & 18 & 7 & 70 \\
\hline Partisan skew & 14 & 0 & 44 \\
\hline $\begin{array}{l}\text { Median } \\
\text { household income } \\
\text { (\$ in 000's) }\end{array}$ & 63 & 28 & 134 \\
\hline \begin{tabular}{l}
$\mathrm{n}=435$, US Congressional Districts, January 2017 \\
\hline
\end{tabular}
\end{tabular}

$45 \%-55 \%$ range. The higher the score the more partisan, and based off the relatively closeness of the popular vote in most elections, a score around 50+ would say the district goes $50+$ in one parties favor, signaling around $95 \%-100 \%$ of the vote for one party. I will use the report from November $7^{\text {th }}, 2016$, as the data from $M y$ Congressional District is meant to represent January $20^{\text {th }}, 2017$ from the census and this is the closest date available.

Above in my data table, the mean, minimum, and maximum for each data set are presented. The sample size for this study is 435 , as there are 435 congressional districts. This excludes the D.C. area, as they do not have congressional representation. For the dependent variable, the unemployment rate, the spread for the unemployment rate coalesces around the 5\% mark, with a minimum of $2.7 \%$ in the $2^{\text {nd }}$ district in Wisconsin and a maximum of $13.4 \%$ in the $15^{\text {th }}$ district of New York, located in the Bronx. The foreign born population averages $13.6 \%$ across the nation, with the maximum percentage of $56.3 \%$ in the $25^{\text {th }}$ district of Florida, which makes sense as the district heavily lies in Miami, which is a population destination for Cuban immigrants. In contrast, the lowest percentage of foreign born population, at $.1 \%$, is in the $6^{\text {th }}$ district of Ohio. I found this to be interesting as the district is in the area which is heavily perceived as old coal and industrial country, where anti-immigrant and anti-free trade sentiments are perceived to be salient amongst citizens. Concerning the issues with populations and congressional districts discussed earlier, the West Virginia's $3^{\text {rd }}$ congressional district has the lowest civilian labor force population at 215,000 , dispelling some worries about that measurement issue. However, the maximum civilian labor force population is 538,000 , is in Montana's at large district. Another interesting statistics result would be that New York's $12^{\text {th }}$ district holds the highest total establishments, New York's $15^{\text {th }}$ holds the highest partisan skew at +44 , and New York's $5^{\text {th }}$ congressional district has the longest travel time to work. All of these districts are within what is considered New York City, emphasizing the potential influence large urban areas may have on these variables.

\section{Empirical Results and Discussion:}

\begin{tabular}{l|c|c|} 
& Coefficient & P-value \\
\hline Intercept: & 9.532 & 0.00 \\
\hline $\begin{array}{l}\text { \% Population } \\
\text { Foreign Born }\end{array}$ & 0.021 & $\begin{array}{c}0.003 * * \\
*\end{array}$ \\
\hline $\begin{array}{l}\text { Civilian Labor } \\
\text { Force (in 000's) }\end{array}$ & -0.011 & $\begin{array}{c}0.000^{* *} \\
*\end{array}$ \\
\hline
\end{tabular}




\begin{tabular}{l|l|l|}
$\begin{array}{l}\text { Avg. Travel } \\
\text { time to work } \\
\text { (min) }\end{array}$ & 0.10 & $\begin{array}{c}0.000^{* *} \\
*\end{array}$ \\
\hline $\begin{array}{l}\% \text { Population } \\
\text { over 25 w BA }\end{array}$ & -0.051 & 0.323 \\
\hline $\begin{array}{l}\text { Total } \\
\text { Establishments } \\
\text { (in 000's) }\end{array}$ & -0.033 & $0.045^{* *}$ \\
\hline Partisanship & 0.012 & $0.086^{*}$ \\
\hline $\begin{array}{l}\text { Family Income } \\
\text { (\$ in 000's) }\end{array}$ & -0.051 & $0.000^{* *}$ \\
\end{tabular}

*** Significant at $1 \%, * *$ Significant at $5 \%, *$ Significant at $10 \%$

\begin{tabular}{|l|l|}
\hline R Square & .4665 \\
\hline Observations & 435 \\
\hline $\begin{array}{l}\text { Dependent } \\
\text { Variable }\end{array}$ & $\begin{array}{l}\text { Unemployment } \\
\text { Rate }\end{array}$ \\
\hline
\end{tabular}

In order to study the relationship between the unemployment rate and the foreign born population in the United States, a regression with all of the previously discussed variables was ran. The results of the study show an R Square value of about .47 , which while relatively low, is still an appropriate number to dissect the conclusions of the regression.

The results for the core independent variable, the foreign born population, are positive and statistically significant. Taking the coefficient value into consideration, the results show that a $1 \%$ increase in the makeup of the foreign born population would lead to an increase in the unemployment rate by $.02 \%$. Using the mean variables from the data summary table, this would show if the \% foreign born population went from $13.6 \%$ to $14.6 \%$, the average unemployment rate would go from $5.4 \%$ to $5.42 \%$. This would show that although a relationship exists between the unemployment rate and the foreign born population exists, the overall effect it has is relatively small. However, the results from the regression are statistically significant at the $1 \%$ level, showing that the small but strong relationship does appear to exist. Therefore, the positive relationship between the unemployment rate and the percent foreign born population can be supported by this study. The hypothesis that a higher foreign born population leads to higher unemployment is therefore accepted.

Before exploring the possible reasons why the foreign born population is found to be statistically significant, the results from the other independent variables bring interesting conclusions. The size of the civilian labor force, the number of establishments, and the median family income were all found to have a positive relationship with the unemployment rate. When the totals of these variables went up, the unemployment rate went down. There are theoretical rationales for why these all make sense. When the civilian labor force is larger, this signals a larger population in the age range of those working, which could increase economic activity on the demand 
side as well. As there are more

establishments in an area, there is a more diverse economy with different job options. Finally, it would make sense that the higher median family income there is, the lower unemployment is as there is more demands for goods and services which creates jobs. It is important to note, however, that the results of the median family income were found to be as statistically significant as the results for the foreign born population and has a stronger change in the unemployment rate. When the median income from a family increases by $\$ 1,000$, the unemployment rate drops $.05 \%$. From the example above, a $\$ 1,000$ increase would drop the average unemployment rate from $5.4 \%$ to $5.35 \%$, showing a more noticeable change in the employment rate.

The independent variable found to be statistically significant that has a negative relationship with the unemployment rate is the average travel to work time of the sampled districts. This would mean that as the average commute time to work of the districts went up, the unemployment rate also went up. This distance measurement makes economic sense, as one could derive from this that the economic benefit of working at a job decreases the longer you have to travel to it. At some point, the commute to work would not be worth it and one would decide to be unemployed and pursue some other need. The results from this variable also produces the largest difference as it increases, as a 1 minute increase in travel time increased the unemployment rate by close to $.10 \%$. Using the average unemployment rate, this would mean that one minute added to the average commute would bring the unemployment rate from $5.4 \%$ to $5.5 \%$. Therefore, traveling to work time represents the most notable change in the unemployment rate in this regression.

The two variables I will discuss before returning to the foreign born population is the educational attainment variable, which is the only statistically insignificant variable in the regression, and the partisan skew variable. I would derive from the statistically insignificant result that while education may heavily influence wages, it may not influence actual employment. There are varying economic sectors with different educational requirements, and a lot of fields that require vocational or trade school are speculated to be undersupplied. When it comes to the partisan skew variable, the results were only significant at the $10 \%$ level and the change was the second smallest with a coefficient of .012. Given the widespread partisanship of the average district $(+14)$, such a small change at a low significant level leaves these variable with questionable results.

The reason why the foreign born population is a significant factor to the unemployment rate in these results could come from a few different sources. One reason why the results would be statistically significant is that in the United States the influx of the foreign born population is not following Say's law. This would mean that the supply of labor that the foreign born population is giving is not being balanced 
out by the demand for goods and services that these same people bring. If this is true, then it would make sense that the results are statistically significant because they would be supplying more labor into the market than demand. One key relationship I would examine is that the median income per family and foreign born population contributes to the unemployment rate. If foreign born populations are struggling financially relative to the average family, they may not be able to demand as many goods. Taken from another perspective, they may also be sending money to family in other countries, which could explain the unbalanced supply and demand given.

As shown by the statistically significant results of most of the independent variables, the unemployment rate can be attributed to a lot of different factors that make or don't make people employable. Trying to explain unemployment through one key factor is likely to fail. While the hypothesis that a higher foreign born population leads to a higher unemployment rate is proven true, there are other variable results which produce stronger effects on the unemployment rate, exemplifying the complexity of explaining the unemployment rate.

\section{Conclusion:}

Through this study, an important issue throughout the history of the United States that has gained renewed prominence in recent political discourse is tackled, as the relationship between the unemployment rate and the foreign born population is explored. By analyzing the current academic literature on the subject, it is shown that results in Europe found a small positive relationship between the two, and in the United States there has generally been a focus on the relationship between wages and the foreign born/immigrant population. Therefore, this research is important as it helps answer whether the focus on wages has been justified or not. In addition, the model of this study grounded the sample in US Congressional Districts, bringing a new level of analysis to the relationship which could help capture the political nature of the issue.

The hypothesis that a higher percentage of a foreign born population would lead to an increase in the unemployment rate is accepted through the econometric results, as the foreign born population is found to be a statistically significant variable included in the model. For a $1 \%$ increase in the $\%$ population foreign born, the unemployment rate increased by $.02 \%$. Other independent variables considered in the congressional districts like the civilian labor force size, the average travel to work time, the partisan skew, the total amount of establishments, and the median family income were all found to be statistically significant in their effects on the unemployment rate. The percentage of the population over 25 years of age and holding a bachelor's degree is the only statistically insignificant independent variable. The independent variable that produces the largest change in the 
unemployment rate, the commute time to work, produces about a $.1 \%$ increase in the unemployment rate per every minute increase in commuting time. This shows that while the foreign born population was a statistically significant variable that leads to an increase in the unemployment rate, it was not the one that produces the greatest change in the unemployment rate.

The results from this study suggest that multiple different policy changes should be considered to improve the unemployment rate. The two variables that produced the highest change in the unemployment rate were the travel time to work and the median family income. Based on the regression results, policy initiatives should be considered which would improve the transportation of employees to work. This could range in investing in more efficient public transportation options for civilians or increasing infrastructure spending. During the 2016 presidential election, a bipartisan concern was funding for a trillion dollar infrastructure bill, and the results of this study suggest that a benefit of such a bill would be lower unemployment. Making commuting to work more economically feasible for workers will increase their willingness to work, which would decrease unemployment. Another policy initiative could be to focus on allowing legal immigrants in who are skilled in job areas with high demand, regardless of the educational attainment of immigrants. This will lead to a better chance of immigrants following Say's law and balancing out their supply of labor and demand of goods as it will be easier for them to find employment in the job market. A final possible policy initiative could be to work towards combating income inequality in the United States. As the median family income in an area had the second biggest change in the unemployment rate, perhaps working towards distributing income towards areas with not a lot of income will help regenerate financially struggling areas and reduce the unemployment rate.

From a research perspective, I would recommend that those who want to study the relationship between the foreign born population and the unemployment rate research characteristics within the foreign born population that would cause them to increase the unemployment rate. As earlier suggested, perhaps foreign born populations have an overall lower median income compared to the median family in the United States. Researching the ways in which foreign born populations are disadvantaged in the job market and other aspects of life and working towards improving these conditions could help bring the foreign born population in the United States to follow Say's law. 


\section{REFERENCES}

Borjas, George. 2006. "Immigration and the American Worker." Center for Immigration Studies 1-26.

Brucker, Herbert and Elke J. Jahn. 2009. "Migration and Wage-Setting: Reassessing the Labor Market Effects of Migration." IAB Nurnberg and IZA Bonn 1-41.

Cochrane, Christopher and Neil Nevitte. 2014. "Scapegoating:

Unemployment, far-right parties and anti-immigrant sentiment." Comparative European Politics 12: 1-32.

Niyimbanira, F. and T.F. Madzivhandila. 2012. "Myth That Immigrants "Steal Jobs": An Economic Blame Game?" International Journal of Social Sciences and Humanity Studies 8: 165-179.

Orozco-Aleman, Sandra and Heriberto Gonzalez-Lozano. 2018. "Labor Market Effects of Immigration Policies Border Enforcement and Amnesty." Journal of Labor Research 39: 150-177.

The Cook Report. 2016. "2016 House Race Ratings." Date accessed 10/14/18 https://www.cookpolitical.com/rating s/house-race-ratings/139361

US Census Bureau. 2017. "My Congressional District". Date accessed 10/14/18. https://www.census.gov/mycd/ 